\title{
GMR
}

\section{Selecting sugarcane genotypes by the selection index reveals high gain for technological quality traits}

\author{
L.A. Silva1 ${ }^{1}$, P.E. Teodoro ${ }^{1}$, L.A. Peixoto ${ }^{1}$, C. Assis $^{2}$, K. Gasparini ${ }^{3}$, \\ M.H.P. Barbosa ${ }^{4}$ and L.L. Bhering ${ }^{1}$ \\ ${ }^{1}$ Departamento de Biologia Geral, Universidade Federal de Viçosa, \\ Viçosa, MG, Brasil \\ ${ }^{2}$ Departamento de Química, Universidade Federal de Viçosa, \\ Viçosa, MG, Brasil \\ ${ }^{3}$ Departamento de Biologia Vegetal, Universidade Federal de Viçosa, \\ Viçosa, MG, Brasil \\ ${ }^{4}$ Departamento de Fitotecnia, Universidade Federal de Viçosa, \\ Viçosa, MG, Brasil \\ Corresponding author: L.L. Bhering \\ E-mail: leonardo.bhering@ufv.br
}

Genet. Mol. Res. 16 (2): gmr16029678

Received March 20, 2017

Accepted April 26, 2017

Published May 25, 2017

DOI http://dx.doi.org/10.4238/gmr16029678

Copyright (C) 2017 The Authors. This is an open-access article distributed under the terms of the Creative Commons Attribution ShareAlike (CC BY-SA) 4.0 License.

\begin{abstract}
Sugarcane (Saccharum $\mathrm{sp}$ ) is one of the most promising crops and researchers have sought for renewable alternative energy sources to reduce $\mathrm{CO}_{2}$ emission. The study of strategies, which allow breeders in the selection of superior genotypes for many traits simultaneously, is important. Therefore, the objectives of this study were: i) to apply path analysis to better understand the relationship between the lignocellulosic traits and technological quality traits with total recoverable sugars (TRS) and ii) to use several multivariate selection indexes to predict the genetic gain and to select superior genotypes in the sugarcane breeding. A total of 40 sugarcane genotypes
\end{abstract}

Genetics and Molecular Research 16 (2): gmr16029678 
were evaluated in an experimental design using incomplete blocks with two replicates. The follow traits were evaluated: dry matter (DM), total soluble solids (BRIX), apparent sucrose content in the juice (POL), apparent sucrose content in sugarcane (POLS), fiber content (FIB), purity (PUR), TRS, lignin content (LC), cellulose content (CC), hemicellulose content (HC), and ash content (AC). These traits were analyzed by analysis of variance, phenotypic correlation network, path analysis, and selection index. The highest direct effect on TRS was obtained by POLS (0.337), POL (0.299), BRIX (0.227), and FIB (-0.146). The estimates of phenotypic correlation between these characters and TRS were in the same direction, which demonstrated a cause-and-effect relationship. The highest indirect effect was of POL via POLS (0.331) followed by POLS via POL (0.294). BRIX presented high indirect effects via POLS (0.266) and via POL (0.246). On the other hand, FIB presented negative indirect effects via POLS (-0.169) and POL (-0.103). In conclusion, path analysis and index selection are useful strategies to help breeders in the selection of superior genotypes in sugarcane.

Key words: Saccharum officinarum; Sugarcane breeding; Sugar; Ethanol; Statistical analysis

\section{INTRODUCTION}

Sugarcane (Saccharum sp) is one of the most promising crops, and researchers have sought for renewable alternative energy sources to reduce $\mathrm{CO}_{2}$ emission (Dias et al., 2013; Carvalho-Netto et al., 2014). Because of this, many countries have become interested in planting sugarcane; besides sugar and ethanol, other products such as straw and bagasse can be used in different ways. The bagasse is a type of lignocellulosic biomass with high energetic potential and can be used widely in the bioenergy production (Sims et al., 2010; Santos et al., 2011, 2012a; Matsuoka et al., 2014).

Currently, the Brazilian sugarcane industry is self-sufficient and sustainable; this makes Brazil the largest producer and exporter country of sugar and ethanol (MAPA, 2016). The breeding contribution has been fundamental for developing varieties with high agronomic quality and high yield (Barbosa et al., 2012). However, the yield should improve considerably to supply the exportation demand of sugar and ethanol (Bertelli, 2012). In fact, it is needed more investment to develop studies related to sugarcane breeding and, consequently, it will be possible to develop varieties more competitive (Barbosa et al., 2012; Sediyama et al., 2012).

Currently, an attractive sugarcane genotype should present high juice quality and a good biomass yield that will be essential to produce biofuel (Mohanraj and Nair, 2014). So, it will be possible to increase the energy production without any increases in the sugarcane cultivation area (Hofsetz and Silva, 2012). To make it possible, breeders should seek for methodologies that allow maximizing the genetic gain in an efficient way for many traits simultaneously.

The use of selection index theory is a useful strategy to obtain gain for several traits simultaneously. Selection index allows combining multiple information obtained in the

Genetics and Molecular Research 16 (2): gmr16029678 
experimental unit in an index by multiple regression. Thus, the selection is based on this index. The breeder should have knowledge about the relationship among traits to make selection index a suitable strategy. Thinking about it, path analysis may help breeders to identify the relationship among the most important traits, and consequently to guide breeders to choose the most suitable selection strategy that can be used in the breeding (Cruz et al., 2012). Recently, several types of research have been performed using selection index and path analyses in sugarcane (Almeida et al., 2014; Dutra Filho et al., 2015; Silva et al., 2016). However, none of them have evaluated the lignocellulosic biomass and technological quality traits.

Therefore, the objectives of this study were: i) to apply path analysis to better understand the relationship between lignocellulosic traits and technological quality traits with total recoverable sugars (TRS) and ii) to use several multivariate selection indexes to predict the genetic gain and to select superior genotypes in the sugarcane breeding.

\section{MATERIAL AND METHODS}

\section{Plant material and trait determination}

A total of 40 sugarcane genotypes from the Active Germplasm Bank of the Sugarcane Breeding Program of the Federal University of Viçosa (PMGCA/UFV) were evaluated in an experimental design using incomplete blocks with two replicates. The PMGCA/UFV makes part of the Inter-University Network for the Development of Sugarcane Industry (RIDESA). The Active Germplasm Bank is composed mostly of exotic genotypes and is located at Fundão Farm, in the municipality of Viçosa, State of Minas Gerais (MG) (latitude 2045'14"S, longitude $42^{\circ} 52^{\prime} 53^{\prime \prime} \mathrm{W}$, and $650 \mathrm{~m}$ in altitude).

From each genotype, 10 stalks were randomly collected by hand and without straw burning, at 18 months after planting. Based on the methodology described in Consecana (2006) estimates for dry matter (DM), total soluble solids (BRIX), apparent sucrose content in the juice (POL), apparent sucrose content in sugarcane (POLS), fiber content (FIB), purity (PUR), and TRS were determined.

The lignin content (LC) was determined using the NREL tests based on the method described by Templeton and Ehrman (1995), and known as Klason lignin (TAPPI, 1998). Cellulose $(\mathrm{CC})$ and hemicellulose contents $(\mathrm{HC})$ were determined by gravimetric analysis (Carrier et al., 2011). The ash content (AC) of the biomass was obtained by the difference between the weight of the ground and dried sugarcane bagasse, before and after incineration in a muffle furnace at $575^{\circ} \mathrm{C}$ for $3 \mathrm{~h}$ (Santos et al., 2014).

\section{Statistical analysis}

Breeding value and genetic parameters were estimated following the equation described below:

$$
y=X f+Z g+W b+\varepsilon
$$

(Equation 1)

where $y$ is the vector of phenotypic value; $f$ is the overall mean; $g$ is the vector of the genotypic effects that was assigned as random; $b$ is the vector of the environment effects that was assigned

Genetics and Molecular Research 16 (2): gmr16029678 
as random; $\varepsilon$ is the vector of the error. $X, Z$, and $W$ are the incidence matrix for the overall mean, genotypic effects, and environment effects, respectively.

Genotypic correlate on between the breeding values was estimated following the equation described below:

$$
r_{G}=\frac{\operatorname{COV}_{\mathrm{G}(\mathrm{xy})}}{\sqrt{\hat{\sigma}_{\mathrm{Gx}}^{2} \times \hat{\sigma}_{\mathrm{Gy}}^{2}}}
$$

where $\mathrm{COV}_{\mathrm{G}(\mathrm{xy})}$ is the phenotypic covariance between the characters $X$ and $Y$; $\hat{\sigma}_{\mathrm{Gx}}^{2}$ is the phenotypic variance for $X$; and $\hat{\sigma}_{\text {Gy }}^{2}$ is the phenotypic variance for $\mathrm{Y}$.

Phenotypic correlation network was used to graphically express the functional relationship between the estimates of the coefficients of phenotypic correlation between traits, in which the proximity between the nodes (traces) is proportional to the absolute value of the correlation between these nodes. The thickness of the edges was controlled by a cut-off value of 0.60 , which means that only $\mid$ rij $\mid \geq 0.60$ has their edges highlighted. Finally, positive correlations were represented in green, whereas negative correlations were represented in red.

Subsequently, the diagnosis of multicollinearity of the correlation matrix $\mathrm{X}^{\prime} \mathrm{X}$ was performed, which revealed severe multicollinearity (condition number $>1000$ ) (Montgomery et al., 2015). Therefore, a constant $\mathrm{K}=0.10$ was added to the diagonal of the matrix $\mathrm{X}^{\prime} \mathrm{X}$ that made a weak multicollinearity (condition number $<100$ ); this made possible to perform path analysis using the correlation matrix. Path analysis was performed using TRS as a principal dependent variable, and it follows the equation described below:

$$
\operatorname{ATR}=\beta_{1} \operatorname{Brix}+\beta_{2} \text { Pol }+\ldots+\beta_{11} \operatorname{Cin}+p_{\varepsilon}
$$

(Equation 3)

where $\beta_{1}, \beta_{2}, \ldots, \beta_{11}$ are the estimators of the direct effect of the traits DM, BRIX, POL, POLS, FIB, PUR, LC, CC, HC, and AC on TRS, and $\mathrm{p}_{\varepsilon}$ is the residual effect.

The coefficient of determination $\left(\mathrm{R}^{2}\right)$ of path analysis was obtained following the equation below:

$$
\mathrm{R}^{2}=\hat{\beta}_{1} \mathrm{r}_{\mathrm{Briz} ; \mathrm{ATR}}+\ldots+\hat{\beta}_{11} \mathrm{r}_{\mathrm{Brix} ; \mathrm{Cin}}
$$

Residual effect $\left(\hat{\mathrm{p}}_{\varepsilon}\right)$ of the path analysis was obtained by the follow equation:

$$
\hat{\mathrm{p}}_{\varepsilon}=\sqrt{1-\mathrm{R}^{2}}
$$

(Equation 5)

Several selection strategies were evaluated aiming to predict the selection gain and select superior genotypes for the evaluated traits simultaneously. Direct and indirect selection, base index (Williams, 1962), multiplicative index (Compton and Empig, 1973), and sum of rank index (Mulamba and Mock, 1978) were evaluated. In this study, the only index that did not need the variance and covariance matrix was used due to the strong multicollinearity among traits. Predicted gain (SG) based on direct selection for the jth trait was estimated according to the equation below:

Genetics and Molecular Research 16 (2): gmr16029678 


$$
S G_{j}=D S_{j} \hat{h}_{j}^{2}
$$

(Equation 6)

where $D S_{j}$ is the differential of selection for the jth trait estimated by the following equation:

$$
D S_{j}=\bar{X}_{s j}-\bar{X}_{o j}
$$

where $\bar{X}_{s j}$ is the selected genotypes mean for the jth trait; $\bar{X}_{o j}$ is the general mean for the jth trait; $\hat{h}_{j}^{2}$ is the broad-sense heritability for the jth trait. Indirect selection gain for the $\mathrm{k}$ trait, by the selection in the $\mathrm{j}$ trait, was estimated by the following equation:

$$
S G_{k(j)}=D S_{k(j)} \hat{h}_{k}^{2}
$$

where $D S_{k(j)}$ is the differential of selection for the $\mathrm{k}$ trait based on the genotypes selected for the $\mathrm{j}$ trait and was estimated by the equation described below:

$$
D S_{k(j)}=\bar{X}_{s k(j)}-\bar{X}_{o k}
$$

where $\bar{X}_{s k(j)}$ is the genotype mean for the $\mathrm{k}$ trait, selected based on the $\mathrm{j}$ trait; $\bar{X}_{o k}$ is the general mean for the $\mathrm{k}$ trait; $\hat{h}_{k}^{2}$ is the broad-sense heritability for the $\mathrm{k}$ trait.

Base index $\left(I_{B}\right)$ were estimated by the equation below:

$$
I_{B}=\sum a_{n} x_{i j}
$$

where $a_{n}$ is the economic weight for the jth trait; $x_{i j}$ is the phenotypic value of the ith genotype for the jth trait. The economic weight vector was defined by 1 to make possible the comparison with another index.

The multiplicative index was estimated by the equation described below:

$$
I_{M}=\prod\left(x_{i j}-\bar{x}_{j}\right)
$$

where $x_{i j}$ is the phenotypic value of the ith genotype for the jth trait; $\bar{x}_{j}$ is the overall mean for the jth trait.

The sum of the rank index $\left(I_{S R}\right)$ was estimated following the equation below:

$$
I_{B}=\sum r_{i j}
$$

where $r_{i j}$ is the genotype classification for the jth trait.

All statistical analyses were performed using the GENES software (Cruz, 2013) and followed the recommended procedures proposed by Cruz et al. (2012).

Genetics and Molecular Research 16 (2): gmr16029678 


\section{RESULTS}

\section{Estimates of genetic parameters and genotypic correlation}

The mean values obtained for the 11 evaluated traits are shown in Table 1 . The traits that characterize the sugar content of the juice, BRIX (17.48), POL (13.73), and POLS (10.72), were low and, consequently, the TRS content (108.92) was lesser than that desired for commercial sugarcane genotypes. On the other hand, the mean for FIB (16.94) was high.

DM and BRIX presented the highest estimates of broad-sense heritability (87 and $59 \%$, respectively; Table 1). Otherwise, the traits AC, PUR, HC, and CC presented the major part of the phenotypic variance explained by the residual variance $\left(\hat{\sigma}_{e}^{2}\right)$ and the variance among block $\left(\hat{\sigma}_{b}^{2}\right)$ and, consequently, the heritability was low for these characters.

Table 1. Estimates of genetic parameters for total soluble solids (BRIX), apparent sucrose content in the juice (POL), dry matter (DM), fiber content (FIB), apparent sucrose content in sugarcane (POLS), purity (PUR), total recoverable sugars (TRS), lignin content (LC), cellulose (CC), hemicellulose contents (HC), and ash content (AC) evaluated in 40 sugarcane genotypes.

\begin{tabular}{l|c|c|c|c|c|c|c}
\hline Trait & $\hat{\sigma}_{g}^{2}$ & $\hat{\sigma}_{b}^{2}$ & $\hat{\sigma}_{e}^{2}$ & $\hat{\sigma}_{f}^{2}$ & $\hat{h}^{2}$ & Accuracy & Mean \\
& 5.84 & 2.63 & 1.49 & 9.96 & 0.59 & 0.77 & 17.48 \\
\hline BRIX & 5.15 & 6.91 & 3.88 & 15.95 & 0.32 & 0.57 & 13.73 \\
\hline POL & 90.10 & 7.55 & 5.89 & 103.54 & 0.87 & 0.93 & 33.73 \\
\hline DM & 3.55 & 0.01 & 4.01 & 7.57 & 0.47 & 0.68 & 16.94 \\
\hline POLS & 3.75 & 4.63 & 2.34 & 10.72 & 0.35 & 0.59 & 10.72 \\
\hline PUR & 5.22 & 58.77 & 106.82 & 170.82 & 0.03 & 0.17 & 77.61 \\
\hline TRS & 305.78 & 346.96 & 163.17 & 815.91 & 0.37 & 0.61 & 108.92 \\
\hline CC & 2.99 & 0.38 & 2.97 & 6.34 & 0.47 & 0.69 & 23.95 \\
\hline HC & 0.11 & 0.17 & 0.45 & 0.73 & 0.15 & 0.38 & 45.90 \\
\hline AC & 0.39 & 0.01 & 3.25 & 3.65 & 0.11 & 0.33 & 22.42 \\
\hline
\end{tabular}

$\hat{\sigma}_{g}^{2}$ : genotypic variance; $\hat{\sigma}_{b}^{2}$ : block variance; $\hat{\sigma}_{e}^{2}:$ residual variance; $\hat{\sigma}_{f}^{2}$ : phenotypic variance; $\hat{h}^{2}:$ broadsense heritability.

Phenotypic network correlation was used aiming to get knowledge about the relationship among the evaluated traits (Figure 1), which is the graphic representation of the traits according to correlation magnitudes between predicted genetic values (BLUPs). Traits with high correlations are closer and connected by more expressive traces, while traits with lower correlation are more distant and connected by thinner traces. The juice quality traits, such as BRIX, POL, POLS, PUR, and TRS, were smaller and more expressive when compared to the other traits, DM, LC, CC, HC, AC, and FIB because the phenotypic correlation among them was higher. Moreover, it was observed that juice quality traits presented negative phenotypic correlation with FIB, which is represented by red traces. Besides this, it is possible to stand out that there was a high negative correlation between $\mathrm{AC}$ and $\mathrm{HC}$. Other traits are more distant to each other, and consequently, they are represented by thinner traces and, therefore, they present low correlation.

\section{Path analysis of TRS}

Path analysis was performed aiming to verify how the traits PLO, POLS, BRIX, PUR,

Genetics and Molecular Research 16 (2): gmr16029678 
FIB, DM, LC, CC, HC, and AC influenced TRS (Table 2). Path analysis also makes possible to estimate the direct and indirect effects on the main dependent trait, i.e., TRS. The correlation of determination had a high magnitude (0.983), and the residual effect had a low magnitude (0.131). Results indicated that almost all TRS variation might be explained by the independent traits.

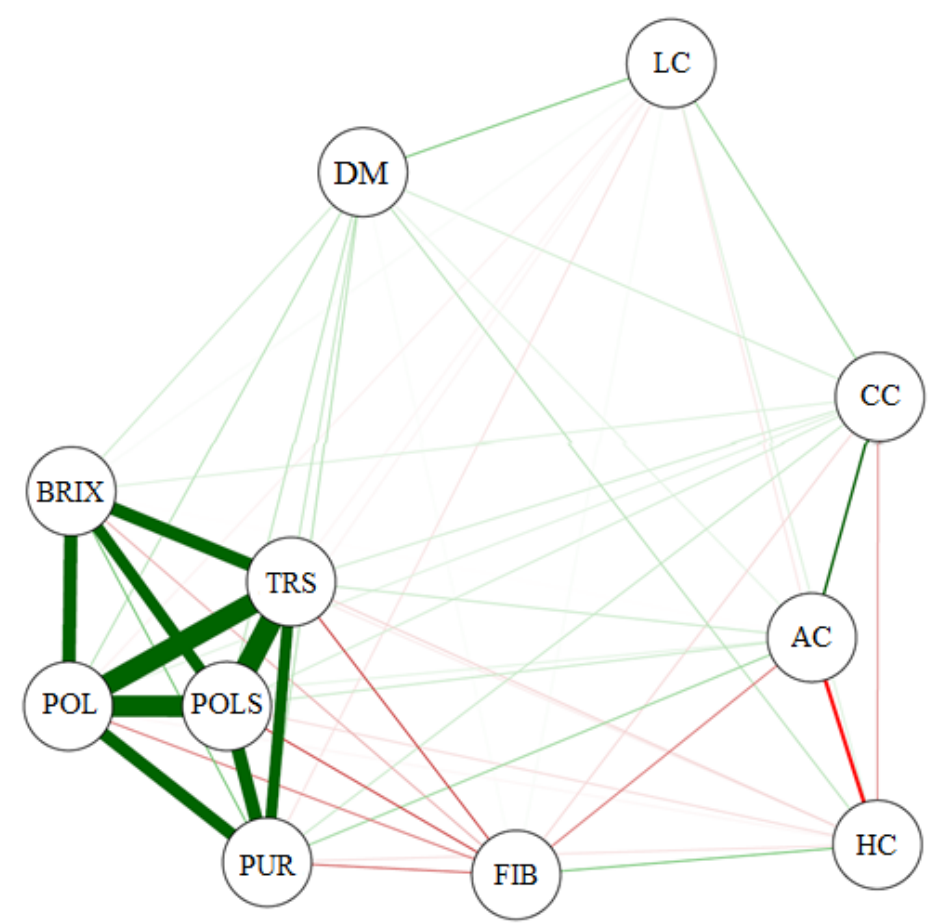

Figure 1. Phenotypic correlation network among the traits total soluble solids (BRIX), apparent sucrose content in the juice (POL), dry matter (DM), fiber content (FIB), apparent sucrose content in sugarcane (POLS), purity (PUR), total recoverable sugars (TRS), lignin content (LC), cellulose (CC), hemicellulose contents (HC), and ash content (AC) evaluated in 40 sugarcane genotypes.

The highest direct effects on TRS were obtained by POLS (0.337), POL (0.299), BRIX (0.227), and FIB (-0.146). The estimates of phenotypic correlation between these characters and TRS were in the same direction, which demonstrated a cause-and-effect relationship. Therefore, if POLS, POL, and BRIX increase, TRS increases as well, otherwise, if FIB content increases, TRS decreases.

Indirect effects were observed, and it contributed to making high magnitude for the TRS variation. The highest indirect effects were of POL via POLS $(0.331)$ followed by POLS via POL (0.294). BRIX presented high indirect effects via POLS (0.266) and via POL (0.246). On the other hand, FIB presented negative indirect effects via POLS (-0.169) and POL (-0.103). Moreover, POL, BRIX, and FIB had indirect effects via POLS greater than their direct effects. Besides this, it was possible to stand out that PUR has influenced TRS with high magnitude, mainly by the indirect way via POLS (0.277) and POL (0.242). However, all direct and indirect effects related to lignocellulosic traits ( $\mathrm{LC}, \mathrm{CC}, \mathrm{HC}$, and $\mathrm{AC}$ ) and DM had low magnitude with TRS, which were lower than the residual $\left(\hat{\mathrm{p}}_{\varepsilon}\right)$.

Genetics and Molecular Research 16 (2): gmr16029678 
Table 2. Estimates of the direct (main diagonal) and indirect effects among the traits total soluble solids (BRIX), apparent sucrose content in the juice (POL), dry matter (DM), fiber content (FIB), apparent sucrose content in sugarcane (POLS), purity (PUR), total recoverable sugars (TRS), lignin content (LC), cellulose (CC), hemicellulose contents (HC), and ash content (AC) evaluated in 40 sugarcane genotypes.

\begin{tabular}{|c|c|c|c|c|c|c|c|c|c|c|c|}
\hline Traits & BRIX & POL & DM & FIB & POLS & PUR & LC & $\mathrm{CC}$ & $\mathrm{HC}$ & $\mathrm{AC}$ & Total \\
\hline BRIX & 0.227 & 0.246 & 0.001 & 0.027 & 0.266 & 0.043 & 0.000 & 0.001 & 0.000 & 0.000 & 0.822 \\
\hline POL & 0.187 & 0.299 & 0.001 & 0.050 & 0.331 & 0.097 & 0.000 & 0.001 & 0.000 & -0.001 & 0.979 \\
\hline DM & 0.025 & 0.051 & 0.005 & -0.002 & 0.056 & 0.023 & -0.001 & 0.001 & 0.000 & -0.001 & 0.159 \\
\hline FIB & -0.042 & -0.103 & 0.000 & -0.146 & -0.169 & -0.050 & 0.000 & -0.001 & 0.000 & 0.007 & -0.511 \\
\hline POLS & 0.179 & 0.294 & 0.001 & 0.073 & 0.337 & 0.099 & 0.000 & 0.001 & 0.000 & -0.003 & 0.998 \\
\hline PUR & 0.082 & 0.242 & 0.001 & 0.061 & 0.277 & 0.120 & 0.000 & 0.002 & 0.000 & -0.005 & 0.786 \\
\hline LC & 0.003 & -0.009 & 0.002 & -0.002 & -0.008 & -0.008 & -0.001 & 0.003 & 0.000 & 0.001 & -0.020 \\
\hline $\mathrm{CC}$ & 0.019 & 0.022 & 0.001 & 0.013 & 0.033 & 0.015 & 0.000 & 0.013 & 0.000 & -0.012 & 0.103 \\
\hline $\mathrm{HC}$ & -0.011 & -0.006 & 0.001 & -0.053 & -0.029 & -0.009 & 0.000 & -0.004 & -0.001 & 0.012 & -0.100 \\
\hline $\mathrm{AC}$ & -0.019 & -0.001 & 0.020 & 0.000 & 0.049 & 0.044 & 0.030 & 0.000 & 0.008 & 0.000 & 0.130 \\
\hline$\hat{R}^{2}$ & \multicolumn{11}{|c|}{0.983} \\
\hline$\hat{p}_{\varepsilon}$ & \multicolumn{11}{|c|}{0.131} \\
\hline
\end{tabular}

\section{Estimates of selection gain}

Estimates of direct and indirect selection gain for 11 evaluated traits were shown in Table 3. The greatest direct and indirect selection gains were obtained for sugarcane technological quality traits (POL, POLS, TRS, PUR, DM, and BRIX). Among them, the highest total gain was verified from the direct selection on POL, POLS, and TRS, which the selection gain were $55.77,54.33$, and $54.33 \%$, respectively.

Selection of lignocellulosic traits presented the lowest total gain and, consequently, they were less efficient in the direct selection seeking to obtain indirect gain for the remaining evaluated traits. Among the lignocellulosic traits, HC had the lowest total gain with selection $(0.29 \%)$.

Table 3. Estimates of direct and indirect selection gain (\%) for total soluble solids (BRIX), apparent sucrose content in the juice (POL), dry matter (DM), fiber content (FIB), apparent sucrose content in sugarcane (POLS), purity (PUR), total recoverable sugars (TRS), lignin content (LC), cellulose (CC), hemicellulose contents (HC), and ash content (AC) evaluated in 40 sugarcane genotypes.

\begin{tabular}{|c|c|c|c|c|c|c|c|c|c|c|c|c|}
\hline \multirow[t]{2}{*}{ Direct selection } & \multicolumn{12}{|c|}{ Indirect selection } \\
\hline & BRIX & POL & DM & FIB & POLS & PUR & TRS & LC & $\mathrm{CC}$ & $\mathrm{HC}$ & $\mathrm{AC}$ & Total \\
\hline BRIX & 10.04 & 7.03 & 8.88 & -1.98 & 8.21 & 0.16 & 7.84 & 1.33 & 0.04 & -0.21 & 0.12 & 41.46 \\
\hline POL & 8.50 & 9.28 & 17.81 & -1.64 & 10.49 & 0.41 & 9.57 & 1.29 & 0.04 & -0.12 & 0.14 & 55.77 \\
\hline DM & 2.35 & 2.45 & 35.65 & -1.04 & 3.22 & 0.09 & 3.01 & 2.45 & 0.08 & 0.18 & 0.04 & 48.48 \\
\hline FIB & -0.97 & -2.49 & -7.81 & 7.61 & -4.34 & -0.21 & -4.02 & -1.40 & -0.01 & -0.27 & 0.00 & -13.91 \\
\hline POLS & 7.91 & 9.20 & 17.91 & -4.17 & 11.08 & 0.44 & 10.13 & 1.76 & 0.05 & -0.12 & 0.14 & 54.33 \\
\hline PUR & 5.09 & 7.89 & 22.82 & -5.21 & 9.96 & 0.48 & 8.95 & 1.27 & 0.03 & -0.11 & 0.17 & 51.34 \\
\hline TRS & 7.91 & 9.20 & 17.91 & -4.17 & 11.08 & 0.44 & 10.13 & 1.76 & 0.05 & -0.12 & 0.14 & 54.33 \\
\hline LC & -2.13 & -2.46 & 5.03 & 1.44 & -3.01 & $\begin{array}{l}-0.13 \\
\end{array}$ & $\begin{array}{l}-2.73 \\
\end{array}$ & 6.04 & 0.06 & 0.17 & \begin{tabular}{ll|}
-0.04 \\
\end{tabular} & 2.24 \\
\hline $\mathrm{CC}$ & 1.56 & 1.10 & 13.00 & 0.37 & 1.33 & 0.01 & 1.29 & 2.92 & 0.24 & 0.41 & 0.14 & 22.37 \\
\hline $\mathrm{HC}$ & $\begin{array}{l}-0.92 \\
\end{array}$ & -0.68 & 0.54 & 3.09 & -1.37 & $\begin{array}{l}-0.01 \\
\end{array}$ & $\begin{array}{l}-1.39 \\
\end{array}$ & 0.20 & 0.03 & 0.83 & \begin{tabular}{ll|}
-0.03 \\
\end{tabular} & 0.29 \\
\hline $\mathrm{AC}$ & 4.25 & 0.55 & -0.19 & -0.36 & 0.53 & -0.13 & 0.83 & 2.18 & 0.00 & -0.03 & -0.35 & 7.28 \\
\hline
\end{tabular}

Total gains estimated by the multiplicative and base index (60.41 and 56.65\%, respectively) were greater than the total gains estimated by the sum of the rank index (51.61\%) and also greater than the total gains estimated by direct and indirect selection (Tables 3 and 4). Individual gains obtained by the multiplicative index were higher than individual gains predicted by the base index for BRIX (7.48), DM (25.91), FIB (-1.42), and LC (1.98).

Genetics and Molecular Research 16 (2): gmr16029678 
The highest estimated gains were obtained using the base index for POL, POLS, PUR, and TRS and also the more significant reduction in FIB (Table 4). Otherwise, the highest predicted gain for BRIX and LC were estimated by the sum of the rank index. The predicted gains for $\mathrm{CC}, \mathrm{HC}$, and $\mathrm{AC}$ were low $(>0.2 \%)$ for all methodologies evaluated in this study.

Table 4. Estimates of the selection gain (\%) using several multivariate selection indexes on 40 sugarcane genotypes.

\begin{tabular}{l|c|c|c|c|c|c|c|c|c|c|c|c}
\hline Selection index & BRIX & POL & DM & FIB & POLS & PUR & TRS & LC & CC & HC & AC & Total \\
\hline Base & 7.38 & 8.87 & 22.41 & -4.57 & 10.82 & 0.44 & 9.89 & 1.13 & 0.07 & 0.05 & 0.16 & 56.65 \\
\hline Multiplicative & 7.48 & 8.27 & 25.91 & -1.42 & 9.3 & 0.38 & 8.47 & 1.98 & 0.05 & -0.03 & 0.02 & 60.41 \\
\hline Sum of ranks & 7.67 & 7.9 & 17.37 & -1.69 & 8.92 & 0.34 & 8.18 & 2.65 & 0.13 & 0.13 & 0.01 & 51.61 \\
\hline
\end{tabular}

BRIX - total soluble solids, POL - apparent sucrose content in the juice, DM - dry matter, FIB - fiber content, POLS - apparent sucrose content in sugarcane, PUR - purity, TRS - total recoverable sugars, LC - lignin content, $\mathrm{CC}$ - cellulose, $\mathrm{HC}$ - hemicellulose contents, and AC - ash content.

\section{DISCUSSION}

Genetic parameters, phenotypic correlation, and path analysis allowed us to identify useful traits to make selection in sugarcane

In the sugarcane breeding, technological quality traits are commonly used for the eventual disposal and selection of genotypes. These characters are usually obtained in routine analysis within their mills, being inexpensive and easy to measure.

The evaluated genotypes presented the low mean value of TRS and high FIB content, considering that the genotypes of sugarcane grown currently contain around 130 to $140 \mathrm{~kg} /$ ton TRS and approximately $12 \%$ FIB. Since the evaluated germplasm bank is composed mostly of exotic genotypes, such results are consistent, and the germplasm bank can be considered an excellent collection of plants that forms a basis for the energy cane breeding (Matsuoka et al., 2014).

The magnitude of the heritability of character is very significant to obtain satisfactory genetic gains with the selection. In this study, DM and BRIX characters could be classified as having high heritability $\left(\mathrm{h}^{2}>0.5\right), \mathrm{CC}, \mathrm{HC}, \mathrm{AC}$, and PUR presented low heritability $\left(\mathrm{h}^{2}<\right.$ 0.15 ), and the other characters showed moderate heritability (Resende, 2002).

Knowledge of the relationship between the characters allows the selection of the main variable, characterized by low heritability and measurement difficulties, being it practiced indirectly or based on other(s), allowing the breeder to get faster progress at a lower cost and hand labor. Noting the network correlations between technological traits that characterized the quality of the juice (BRIX, POL, POLS, TRS, PUR, and FIB) formed a group where all are strongly correlated.

Currently, one of the criteria for determining the economic value of sugarcane is the system that uses as a base the quality of the sugarcane expressed by the concentration of TRS (sucrose, glucose, and fructose) in the industrial process. This set of sugars is called TRS contained in a ton of cane and is determined based on the content of sugars, fiber, and juice purity (Costa et al., 2015; Micheletti et al., 2016); this makes the TRS one of the most important characters when the objective is to select superior genotypes of sugarcane in breeding programs.

However, estimates of genetic parameters showed that measuring the TRS can be difficult due to the high environmental influence and low estimates of heritability and selective accuracy. One way to assist the auxiliary genetic progress is to identify characters that have

Genetics and Molecular Research 16 (2): gmr16029678 
cause and effect relationship with the TRS, besides being easier and greater selective accuracy. With this is mind, the path analysis was performed considering the TRS as the main variable, which showed that all its variation could be explained by other traits.

Among the traits evaluated, those that can assist in the indirect selection are POL, POLS, BRIX, and FIB, which have direct effects on the TRS and genotypic correlations in the same direction, and high heritability and accuracy as the main dependent variable. These characters had indirect effects exerted upon each other with a magnitude (in modulus) higher than the residual effect, indicating that selection index must be constructed to assist the genetic gain in the main traits of interest.

BRIX is one of the main technological properties evaluated in sugarcane and can be estimated accurately on the field even before harvest. This character along with high heritability showed high correlations with other technological properties, confirmed by path analysis, and this also ensures that with the direct selection of genotypes with high BRIX content, there will be an indirect selection of genotypes with high sugar content and lower fiber content to be shipped to the next stage in a sugarcane breeding.

In addition to the technological analysis to determine the percentage of fiber, currently, analyses are carried out to characterize it according to the lignin, cellulose, hemicellulose, and ashes for better use of this biomass for bioenergy production (Santos et al., 2012a, 2014). However, the methodologies used to determine the chemical composition of lignocellulosic material are more expensive, time-consuming, and require skilled labor. In this case, the existence of significant correlations of these traits with the technological properties would be desirable.

Among the lignocellulosic traits, only lignin had moderate heritability and can be used for direct selection of genotypes with more efficient biomass for burning, as a greater proportion of higher total lignin will be converted to charcoal, due to its higher resistance to thermal degradation (Santos et al., 2012b). The other lignocellulosic characters showed heritability considered of low magnitude and highly influenced by environmental factors. Moreover, these lignocellulosic traits showed low correlation and low effect on the TRS variable in the path analysis, and it is, therefore, inefficient in the indirect selection of characters.

\section{Multivariate selection index allowed us to maximize the gain selection in sugarcane}

The sugarcane technological quality traits were the most efficient in the direct selection providing greater gains simultaneously in all traits evaluated. Among these technological traits, PUR and DM are not considered efficient to practice selection since the first showed low heritability and the second had most of its total gain explained by direct selection causing small indirect gains in all other characteristics.

As discussed earlier, a way to speed up the selection process and eliminate timeconsuming measurements is the selection of strongly correlated traits to the character of interest that are easy to measure. In this case, BRIX would be more suitable. However, it caused the lowest total gain and indirect gain in the TRS variable when compared to the selection of POL, POLS, and TRS. Thus, to obtain higher gains with the direct and indirect selection, direct selection of POL should be considered, since it features moderate heritability, high correlation with technological traits and it enabled the prediction of the higher total genetic gain and better indirect gains. This variable consists of the content of the sucrose broth, determined by saccharimetric methods (polarimeters or saccharimeters); its determination is a little more laborious, and its estimate depends on the BRIX estimate.

Genetics and Molecular Research 16 (2): gmr16029678 
However, the higher total genetic gains were predicted when multiplicative and base index were used, which allowed total gain higher when compared to a direct selection of any evaluated characteristic. On the other hand, these selection indexes provided reduced gains on some characters, which can be offset by better distribution of favorable gains in other characters. Pedrozo et al. (2009) verified that the multiplicative index showed a high efficiency in the selection of superior genotypes of sugarcane, which could increase the chance of success in the sugarcane breeding.

Different indexes provide different alternatives for selection and different gains, and the genotypes can be shown as more or less suitable for the purpose of the breeder in a quick and efficient fashion (Cruz et al., 2012). Another advantage of multivariate selection indexes used in this field is that they do not require inversion of the phenotypic covariance matrix like most of the selection indexes. The multicollinearity detected here is consistent because the high association between the characters is not a problem, and consequently, it does not affect in predicting genetic gains with a selection of the best genotypes.

\section{Conflicts of interest}

The authors declare no conflict of interest.

\section{ACKNOWLEDGMENTS}

We thank CAPES (Coordenação de Aperfeiçoamento de Pessoal de Nível Superior), CNPq (Conselho Nacional de Desenvolvimento Científico e Tecnológico), FAPEMIG (Fundação de Amparo à Pesquisa do Estado de Minas Gerais), FUNARBE (Fundação Arthur Bernardes), and Universidade Federal de Viçosa for financial support.

\section{REFERENCES}

Almeida LM, Viana AP, Amaral Júnior AT, Júnior C, et al. (2014). Breeding full-sib families of sugar cane using selection index. Cienc. Rural 44: 605-611. https://doi.org/10.1590/S0103-84782014000400005

Barbosa MHP, Resende MDV, Dias LAS, Barbosa GVS, et al. (2012). Genetic improvement of sugar cane for bioenergy: the Brazilian experience in network research with RIDESA. Crop Breed. Appl. Biotechnol. 12: 87-98. https://doi. org/10.1590/S1984-70332012000500010

Bertelli LG (2012). O etanol continuará a ser a estrela na área de energia na próxima década. Rev. Hemisf. Agroenerg. 1: $17-18$.

Carrier M, Loppinet-Serani A, Denux D, Lasnier J-M, et al. (2011). Thermogravimetric analysis as a new method to determine the lignocellulosic composition of biomass. Biomass Bioenergy 35: 298-307. https://doi.org/10.1016/j. biombioe.2010.08.067

Carvalho-Netto OV, Bressiani JA, Soriano HL, Fiori CS, et al. (2014). The potential of the energy cane as the main biomass crop for the cellulosic industry. Chem. Biol. Technol. Agricul 1: 20. https://doi.org/10.1186/s40538-014-0020-2

Compton W and Empig L (1973). Comparison of the efficiencies of selection indices for three traits in two variety crosses of corn. Crop Sci. 13: 184-186.

Consecana (2006). Conselho dos produtores de cana de-açúcar, açúcar e álcool do Estado de São Paulo, Piracicaba.

Costa JAB, Ponciano NJ and de Souza PM (2015). Avaliação da sistemática de cálculos para efeito de pagamento de cana pelos açúcares totais recuperáveis (Atr) nos estados do Rio de Janeiro, Espírito Santo e São Paulo. InterSci. Place 1 (7).

Cruz CD (2013). GENES - a software package for analysis in experimental statistics and quantitative genetics. Acta Sci. Agron. 35: 271-276. https://doi.org/10.4025/actasciagron.v35i3.21251

Cruz CD, Regazzi AJ and Carneiro PCS (2012). Modelos biométricos aplicados ao melhoramento genético. UFV, Viçosa.

Dias MO, Junqueira TL, Cavalett O, Cunha MP, et al. (2013). Cogeneration in integrated first and second generation

Genetics and Molecular Research 16 (2): gmr16029678 
ethanol from sugarcane. Chem. Eng. Res. Des. 91: 1411-1417. https://doi.org/10.1016/j.cherd.2013.05.009

Dutra Filho JA, Junior TC and Simões Neto DE (2015). Genetic analyses, phenotypic adaptability and stability in sugarcane genotypes for commercial cultivation in Pernambuco. Genet. Mol. Res. 14: 12102-12110. https://doi. org $/ 10.4238 / 2015$.October.5.23

Hofsetz K and Silva MA (2012). Brazilian sugarcane bagasse: energy and non-energy consumption. Biomass Bioenergy 46: 564-573. https://doi.org/10.1016/j.biombioe.2012.06.038

MAPA (2016). Ministério da agricultura, pecuária e abastecimento.

Matsuoka S, Kennedy AJ, Santos EGD, Tomazela AL, et al. (2014). Energy cane: its concept, development, characteristics, and prospects. Adv. Bot. Res. 2014: 10.1155/2014/597275.

Micheletti RN, Zera FS, Garcia JRM and do Amaral NC (2016). Rentabilidade da produção de cana-de-açúcar sob dois tipos de contrato de venda. Nucleus 13: 271-282. https://doi.org/10.3738/1982.2278.1681

Mohanraj K and Nair N (2014). Biomass potential of novel interspecific hybrids involving improved clones of Saccharum. Ind. Crops Prod. 53: 128-132. https://doi.org/10.1016/j.indcrop.2013.12.004

Montgomery DC, Peck EA and Vining GG (2015). Introduction to linear regression analysis. John Wiley \& Sons, New Jersey.

Mulamba NN and Mock JJ (1978). Improvement of yield potential of the Eto Blanco maize (Zea mays L.) population by breeding for plant traits. Egypt. J. Genet. Cytol. 7: 40-51.

Pedrozo CÂ, Benites FRG, Barbosa MHP, de Resende MDV, et al. (2009). Eficiência de índices de seleção utilizando a metodologia REML/BLUP no melhoramento da cana-de-açúcar. Sci. Agraria 10: 031-036.

Resende MDV (2002). Genética biométrica e estatística no melhoramento de plantas perenes. Embrapa Informacao Tecnológica, Brasília.

Santos FA, Queiróz JH, Colodette JL, Fernandes SA, et al. (2012a). Potential of sugarcane straw for ethanol production. Quim. Nova 35: 1004-1010. https://doi.org/10.1590/S0100-40422012000500025

Santos FA, Queiroz JH, Colodette JL, Manfredi M, et al. (2014). Optimization of hydrothermal pretreatment of cane sugar straw for cellulosic ethanol production. Quim. Nova 37: 56-62. https://doi.org/10.1590/S0100-40422014000100011

Santos ML, Lima OJ, Nassar EJ, Ciuffi KJ, et al. (2011). Study of the storage conditions of the sugarcane bagasse through thermal analysis. Quim. Nova 34: 507-511.

Santos RC, Carneiro ACO, Trugilho PF, Mendes LM, et al. (2012b). Thermogravimetric analysis of eucalyptus clones as a subside for charcoal production. Cerne 18: 143-151.

Sediyama CS, Carneiro JES, Fritsche-Neto R, Sediyama T, et al. (2012). Contribution of the universities to the development of field crop cultivars. Crop Breed. Appl. Biotechnol. 12: 121-130. https://doi.org/10.1590/S1984$\underline{70332012000500013}$

Silva LA, Resende RT, Ferreira RA, Silva GN, et al. (2016). Selection index using the graphical area applied to sugarcane breeding. Genet. Mol. Res. 15. https://doi.org/10.4238/gmr.15038711

Sims RE, Mabee W, Saddler JN and Taylor M (2010). An overview of second generation biofuel technologies. Bioresour. Technol. 101: 1570-1580. https://doi.org/10.1016/j.biortech.2009.11.046

TAPPI (1998). TAPPI Test Method T-222 OM-88. “Acid-Insoluble Lignin in Wood and Pulp”. Technical Association of the Pulp and Paper Industry, Atlanta, GA.

Templeton D and Ehrman T (1995). Chemical analysis and testing task: LAP-003 (Determination of acid-insoluble lignin in Biomass) National Renewable Energy Laboratory. Golden, USA.

Williams J (1962). The evaluation of a selection index. Biometrics 18: 375-393. https://doi.org/10.2307/2527479

Genetics and Molecular Research 16 (2): gmr16029678 